\title{
Assessment of salinity hazard in existing water resources for irrigation and potentiality of conjunctive uses: a case report from Gopalganj District, Bangladesh
}

\author{
Mashura Shammi ${ }^{1,2}$ (D) Rashadur Rahman ${ }^{1}$ Md. Mostafizur Rahman ${ }^{1,3} \cdot$ \\ Md. Moniruzzaman ${ }^{4} \cdot$ Md. Bodrud-Doza $^{1} \cdot$ Bikash Karmakar $^{1} \cdot$ M. Khabir Uddin ${ }^{1}$
}

Received: 13 November 2015/Accepted: 31 August 2016/Published online: 12 September 2016

(C) Springer International Publishing Switzerland 2016

\begin{abstract}
A total of 21 water samples were collected from surface water (ponds and river) and groundwater samples from shallow tube well (STW) and deep tube well (DTW) from Gopalganj Sadar Upazila to evaluate the salinity hazard and suitability for irrigation purposes. Both surface and groundwater of the study area maintained the trend of $\mathrm{Cl}^{-}>\mathrm{SO}_{4}{ }^{2-}>\mathrm{PO}_{4}{ }^{3-}$. The cation trend in both surface and groundwater of the study area was $\mathrm{Na}^{+}>\mathrm{K}^{+}>$ $\mathrm{Ca}^{2+}>\mathrm{Mg}^{2+}>\mathrm{Fe}$. Correlation matrices and principal component analysis (PCA) confirmed the stress of salinity from elevated electrical conductivity and total dissolved solids (TDS) with $\mathrm{Na}^{+}, \mathrm{K}^{+}, \mathrm{Cl}^{-}$and total hardness (TH) in relation to $\mathrm{Ca}^{2+}, \mathrm{Mg}^{2+}, \mathrm{PO}_{4}{ }^{3-}$ and $\mathrm{SO}_{4}{ }^{2-}$. Salinity hazard classification and Wilcox diagram for irrigation water classification demonstrate that shallow tube wells containing low alkali and low sodium hazard are an excellent source of irrigation waters and fall under good to fair class of water (55\% samples). Higher TH, sodium adsorption ratio (SAR), soluble sodium percentage (SSP) and other important analysis indicated that most of the surface water and DTW were not suitable for irrigation. Therefore, the
\end{abstract}

Mashura Shammi

mashura926@gmail.com

1 Department of Environmental Sciences, Jahangirnagar University, Dhaka, Bangladesh

2 Department of Environmental Pollution and Process Control, Xinjiang Institute of Ecology and Geography, Chinese Academy of Sciences, Urumqi 830011, Xinjiang, People's Republic of China

3 Faculty of Environmental Earth Science, Graduate School of Environmental Science, Hokkaido University, Sapporo, Japan

4 Soil, Agronomy and Environment, BCSIR, Dhaka, Bangladesh best irrigation water quality was from STW. Nevertheless, to sustainably and efficiently utilize the existing water resources, cyclic conjunctive uses of river water, STW and DTW as well as excavation of pond to store rainwater were suggested.

Keywords Salinity hazard - Irrigation - Conjunctive water uses - Sodium adsorption ratio (SAR) - Soluble sodium percentage (SSP) · Electrical conductivity (EC) · Principal component analysis (PCA)

\section{Introduction}

Bangladesh is an irrigated agriculture-based country and is dependent on adequate water supply of usable quality. As the crop yield is directly related to the quality of water used for irrigation, an assessment of groundwater suitability for irrigation is essential for the growth of food production and poverty eradication (Shahid et al. 2006). Coastal Bangladesh, covering about 3.22 million ha, of which 2.00 million ha are cultivable land (SRDI 2001), used to have great potential for agricultural development, but increasing salinity, mainly in the soils root zone, is the largest limiting factor (Rahman et al. 1993). Previously, water quality concerns have often been neglected because good-quality water supplies have been plentiful and readily available (Islam and Shamsad 2009). However, salinity increase has been one of the major problems for traditional agricultural practices in coastal Bangladesh for several decades (Rahman et al. 2011). The number of non-saline areas attacked by the salinity problem had increased within the last few decades and the agricultural production of those areas is also affected. The freshly deposited alluviums from upstream in the coastal areas of Bangladesh become saline 
as it comes in contact with the seawater and continues to be inundated during high tides and ingress of seawater through creeks. The factors which contributes significantly to the development of saline soils are tidal flooding during the wet season (June-October), direct inundation by saline or brackish water and upward or lateral movement of saline groundwater during the dry season (November-May) (Haque et al. 2006).

The water resources sustainability largely depends on the proper management and efficient utilization of agricultural water (Fasakhodi et al. 2010). In this regard, the conjunctive use of surface water and groundwater resources can not only solve the problem of water shortages, but also improve the water uses of existing water resources efficiently (Liu et al. 2013). The simultaneous use of two water sources, i.e., surface water and groundwater for irrigation, is referred to as conjunctive use (Foster and van Steenbergen 2011). Generally, the conjunctive water use improves the availability and reliability of water which results in improved water use efficiency. The utilization of saline water for irrigation is challenging (Singh 2014). It poses serious threats to agricultural sustainability and food security by increasing salt buildup in the root zone; however, salinity balance of the irrigation system has to be maintained for long-term sustainable agricultural production (Tyagi 2003). Conjunctive use can allow the utilization of poor-quality saline surface water and or groundwater resources with freshwater for irrigation (Kaur et al. 2007). The conjunctive use of poor-quality water for irrigation improves the overall crop production and helps in achieving the food security for the burgeoning global population (Singh 2014).

Conditions of water quality and quantity are two key factors impacting groundwater utilization for irrigation (Jang et al. 2012). In terms of irrigation water quality of the hydrochemical characteristics, very few studies were conducted in the coastal districts of Bangladesh. Reported impacts would include sea level rise on river salinity in the Gorai River network (Bhuiyan and Dutta 2012); rising salinity occurrences in Kumar-Madhumati River during pre-monsoon which is also within the network of Gorai River (Shammi et al. 2012); hydrochemical characteristics and quality assessment of shallow groundwater (Bahar and Reza 2010). Rahman et al. (2012) assessed the groundwater quality of deep aquifer for irrigation in the southwestern zone of Bangladesh and found that the northern deep groundwater had the highest salinity and other chemical concentrations showed a decreasing trend toward the south (Rahman et al. 2012). However, some of the detailed investigations regarding the extent of salinity hazard in the irrigation water quality and its suitability for crops have not yet been done in the this area. Most of the people of these districts are dependent on agriculture and crop production, which is highly dependent on goodquality irrigation water. It is very much important to assess the salinity hazard of the existing water resource for saline-affected areas. Keeping these in mind, the objective of the research was to assess the hydrochemistry of the surface water and groundwater and to evaluate the suitability of irrigation water quality of different sources of Gpalgonj Districts in Bangladesh and of choosing the best method for conjunctive uses to ensure sustainable water resource management.

\section{Materials and methods}

\section{Sample collection and analysis}

The study area Gopalganj Sadar Upazila of Gopalganj District is situated in Dhaka division of Bangladesh with latitude $23^{\circ} 20^{\prime}$ to $22^{\circ} 50^{\prime}$ north and $90^{\circ} 05^{\prime}$ to $89^{\circ} 40^{\prime}$ east The water samples were collected from various irrigation sources in the pre-monsoon season in the month of March 2012. Three pond water samples (S-2 to $S-4)$, five river water samples (S-1 and S-5 to S-8), eight shallow tube well (STW) samples (S-9 to S-18) and three deep tube well (DTW) samples (S-19 to S-21) were collected (Fig. 1) and preserved in $500 \mathrm{~mL}$ plastic PET bottles according to the standard methods mentioned in APHA (1998). The depth of the STW varied from 100 to 150 feet, while the depth of DTW was more than 600 feet. Two sets of the same sample were collected from each location. One set of samples was kept under non-acidified condition and another under acidified condition by adding $0.01 \mathrm{M}$ nitric acid.

The physical parameters electrical conductivity (EC), $\mathrm{pH}$ and DO were measured using potable TOA-DKK meters instantly at the site with the probe model HM 30P, DO 31P and CM 31P, respectively. All parameters were measured three times. Only highly pure analytical grade chemicals and double distilled water were used for preparing the solution for analysis according to the method described elsewhere (Huq and Alam 2005). $0.45 \mu \mathrm{m}$ polycarbonate filter paper was used for filtering water samples. For determining the concentration of $\mathrm{Ca}^{2+}$, and $\mathrm{Mg}^{2+}$, the samples were directly run into the atomic adsorption spectrometer (AAS) (Shimadzu AA-7000 series). Sulfate $\left(\mathrm{SO}_{4}{ }^{2-}\right)$ and phosphate $\left(\mathrm{PO}_{4}{ }^{3-}\right)$ were determined by UV-spectrophotometer model no. SPECORD222A433 at $420 \mathrm{~nm}$ by the turbidimetric method (using Tween-80) and $490 \mathrm{~nm}$ wavelength by vanado-molybdate phosphoric yellow color method in $\mathrm{mg} /$ $\mathrm{L}$ (Huq and Alam 2005). Chloride $\left(\mathrm{Cl}^{-}\right)$was determined by the volumetric method. Sodium $\left(\mathrm{Na}^{+}\right)$and potassium $\left(\mathrm{K}^{+}\right)$ were determined by the flame photometer (Model No. Jencons, PFP7). 
Fig. 1 Sampling sites of Gopalganj Sadar Upazila of Gopalganj District, Bangladesh

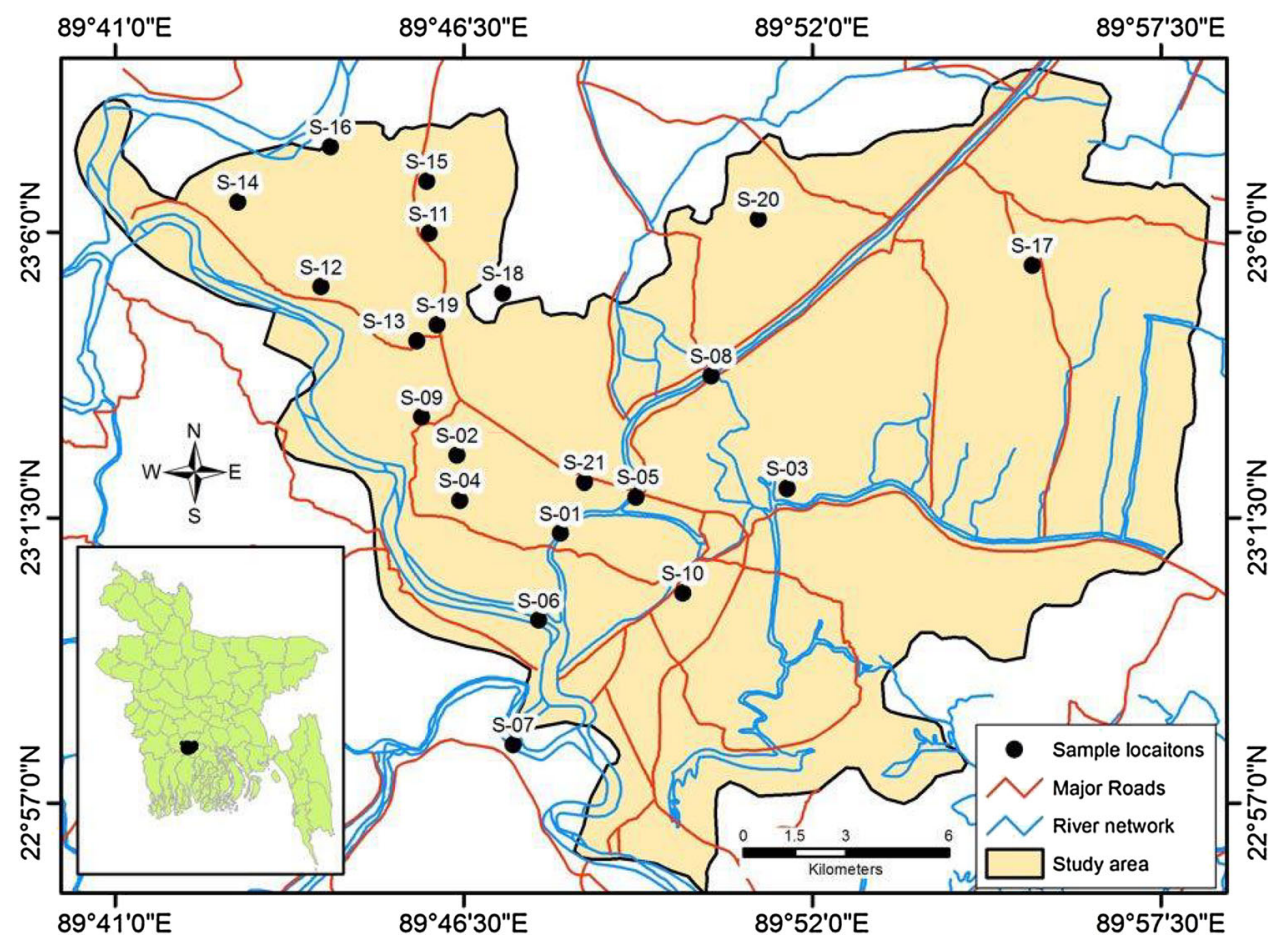

The sodium adsorption ratio (SAR) describes the relationship between soluble $\mathrm{Na}^{+}$and soluble divalent cations $\left(\mathrm{Ca}^{2+}\right.$ and $\left.\mathrm{Mg}^{2+}\right)$ (Alrajhi et al. 2015). It is a measure of the sodicity of the soil determined through quantitative chemical analysis of water in contact with it. The sodium adsorption ratio (SAR) was calculated by the following equation given by Richards (1954):

$\mathrm{SAR}=\frac{\mathrm{Na}^{+}}{\sqrt{\frac{\mathrm{Ca}^{2+}+\mathrm{Mg}^{2+}}{2}}}$,

where all the ions are expressed in meq/L.

SAR was plotted against EC $(\mu \mathrm{S} / \mathrm{cm})$ on the US salinity diagram to categorize the analyzed water samples according to their irrigational suitability quotient. This has long been the standard measure of potential sodium hazard for irrigation water (USDA/Salinity Laboratory Staff 1954). Soluble sodium percentage (SSP) or $\left(\% \mathrm{Na}^{+}\right)$is also used to evaluate the sodium hazard. Water with an SSP greater than $60 \%$ may result in sodium accumulations that will cause a breakdown in the soil's physical properties (Khodapanah et al. 2009). SSP was calculated by the following equation (Todh 1980):

$\mathrm{SSP}=\frac{\left(\mathrm{Na}^{+}+\mathrm{K}^{+}\right) \times 100}{\left(\mathrm{Ca}^{2+}+\mathrm{Mg}^{2+}+\mathrm{Na}^{+}+\mathrm{K}^{+}\right)}$,

where all the ions are expressed in meq/L.

The SSP and EC values have been plotted on the Wilcox diagram (Wilcox 1948) for identifying the classification of sample water for irrigation.
Total hardness $(\mathrm{TH})$ and magnesium adsorption ratio (MAR) were calculated by the equation proposed previously by (Raghunath 1987):

$\mathrm{TH}=\mathrm{Ca}^{2+} \times \mathrm{Mg}^{2+} \times 50$,

where $\mathrm{TH}$ is expressed in $\mathrm{mg} / \mathrm{L}$.

MAR $=\frac{\mathrm{Mg}^{2+} \times 100}{\mathrm{Mg}^{2+}+\mathrm{Ca}^{2+}}$,

where all the ionic concentrations are expressed in meq/L.

Kelly's ratio (KR) is also an important parameter for irrigation water quality, which is measured considering sodium ion concentration against calcium and magnesium ion concentrations. $\mathrm{KR}>1$ indicates an excess level of $\mathrm{Na}^{+}$ in water, whereas $\mathrm{KR}<1$ is suitable for irrigation. $\mathrm{KR}$ ratio more than $>3$ is unsuitable for irrigation. KR was calculated using the equation (Kelly 1963) as:

Kelly's Ratio $=\frac{\mathrm{Na}^{+}}{\mathrm{Ca}^{2+}+\mathrm{Mg}^{2+}}$,

where all the ionic concentrations are expressed in meq/L.

\section{Data analysis}

Data were input by Microsoft office Excel 2007 and statistical analysis of the dataset of Pearson's correlation coefficient matrix (2-tailed test of at the $0.05 \%$ level). Multivariate statistics principal component analysis (PCA) was performed in Origin 9.0 (OriginLab, USA). The spatial distribution map of EC was prepared by ArcGIS (version 


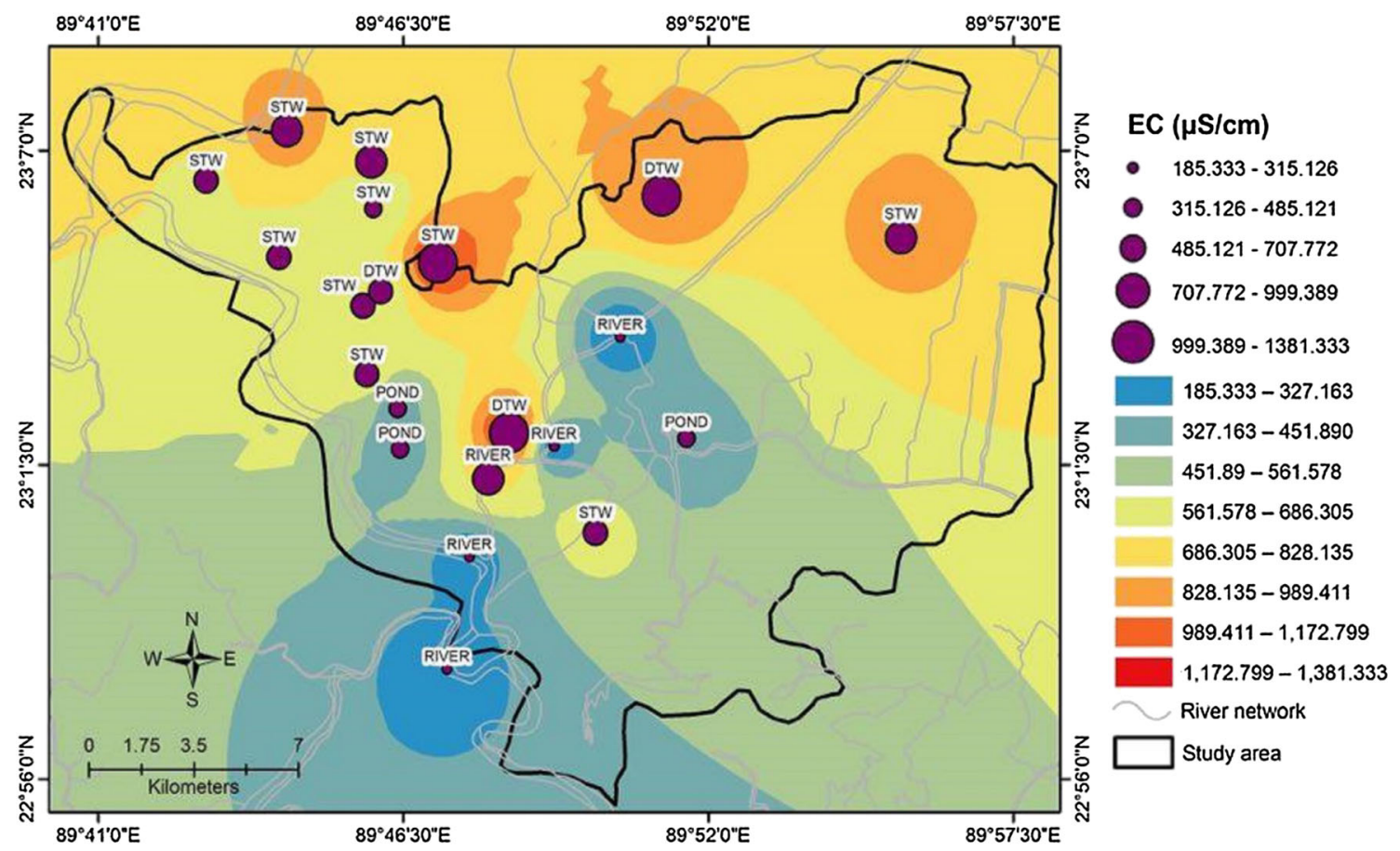

Fig. 2 Spatial distribution of electrical conductivity (EC) found in the surface water of river and ponds and groundwater in deep tube wells indicated as DTW and shallow tube wells indicated as STW

10.1) adopting inverse distance weighted (IDW) method (Isaaks and Srivastava 1989).

\section{Results and discussion}

Surface water $\mathrm{pH}$ varied from 7.5 to 9.6 with the average value of 8.24. Average $\mathrm{pH}$ value of groundwater ranged from 6.89 to 7.78 . All the values were within the permissible limit (6.5-8.5) of MOEF/DoE/GOB for irrigation in agriculture (1997). Electrical conductivity (EC) of surface water samples of the study area varied from 185 to $727 \mu \mathrm{S} /$ $\mathrm{cm}$ with an average value of $318 \mu \mathrm{S} / \mathrm{cm}$, which are according to Wilcox (1948) irrigation water quality classification "Excellent" (Fig. 2). EC values ranged from 475 to $1382 \mu \mathrm{S} / \mathrm{cm}$ with an average value of $756.30 \mu \mathrm{S} / \mathrm{cm}$ for STW and $977 \mu \mathrm{S} / \mathrm{cm}$ for DTW, which are within the acceptable limits of $2250 \mu \mathrm{S} / \mathrm{cm}$ set by MOEF/DoE/GOB (1997). The STW is also considered as "excellent" irrigation water quality classification, while due to higher EC content DTW water is considered as "good". The spatial distributions of EC $(\mu \mathrm{S} / \mathrm{cm})$ of different sources of irrigation water are shown in Fig. 3. The total dissolved solid (TDS) values for surface water ranged from 118.4 to 465.28 to $465.28 \mathrm{mg} / \mathrm{L}$, and the average value was 203.544 $\mathrm{mg} / \mathrm{L}$. The average value of river water TDS was 122.92 $\mathrm{mg} / \mathrm{L}$. The STW and DTW water sample had an average TDS value of 484.03 and $628.28 \mathrm{mg} / \mathrm{L}$, respectively

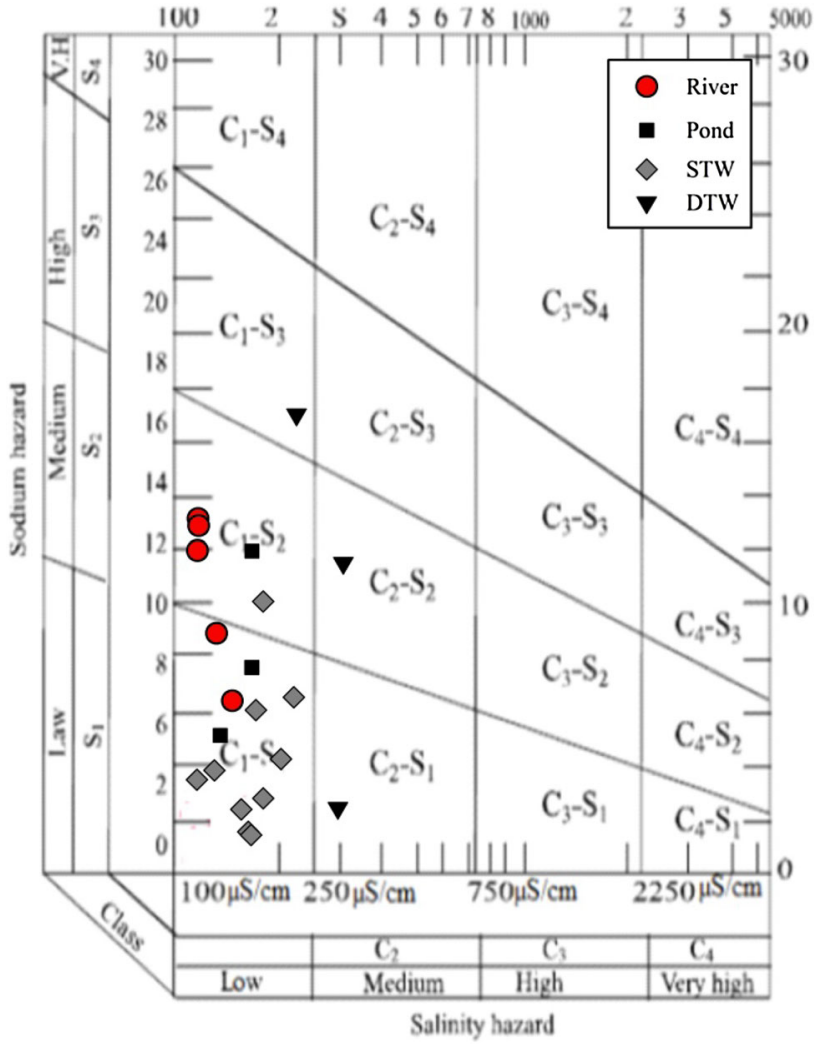

Fig. 3 Salinity hazard classification of the sampling site according to the US Salinity Laboratory's diagram 


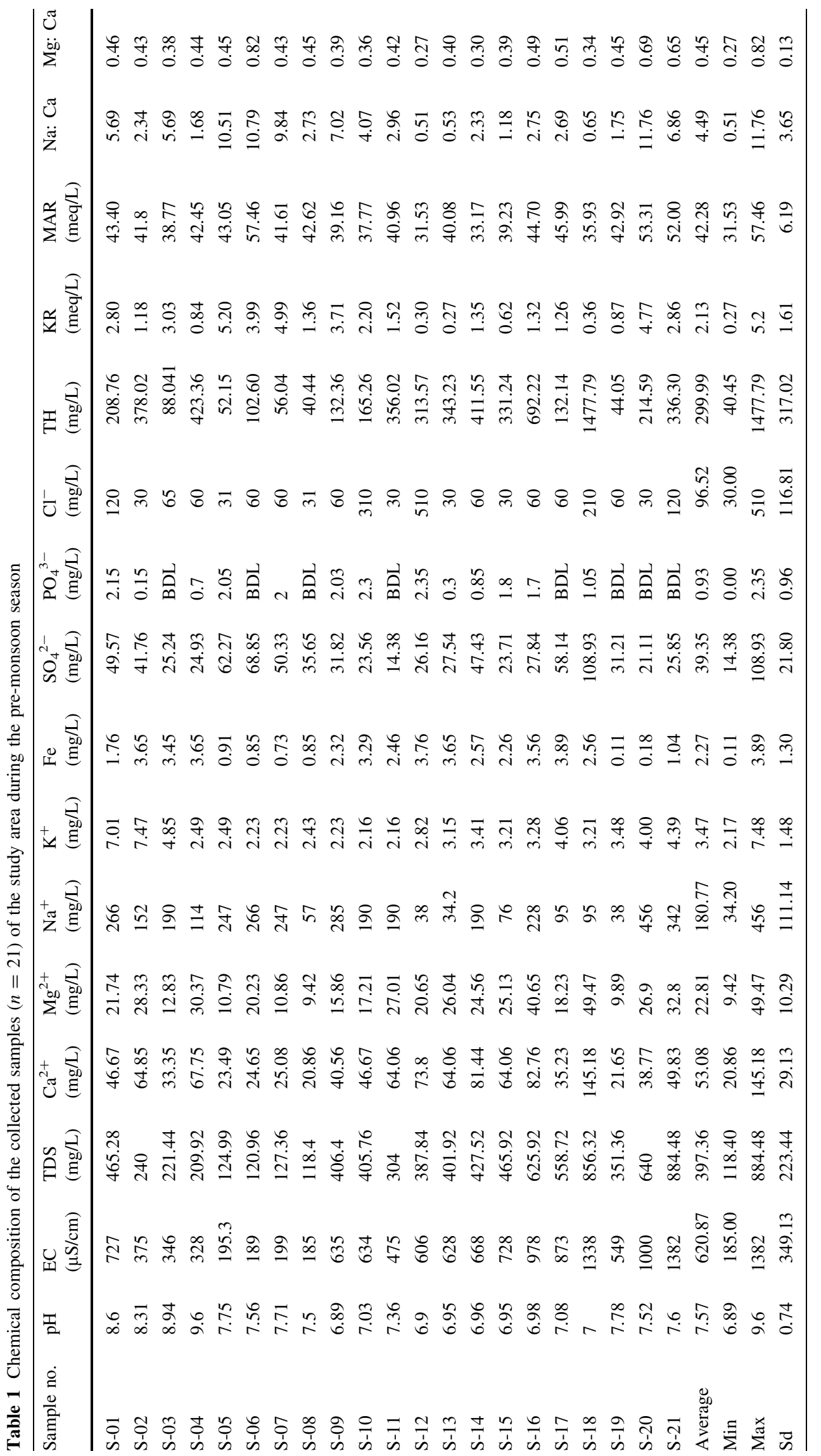


(Table 1). The values of both surface water and groundwater are within the acceptable limit of $1000 \mathrm{mg} / \mathrm{L}$ set by MOEF/DoE/GOB (1997).

It is evident that all the values of $\mathrm{K}^{+}, \mathrm{Ca}^{2+}$ and $\mathrm{Mg}^{2+}$ in the surface and groundwater of the study area were lower than the recommended limit and can be used without restriction (Table 1). The cation trend in both surface and groundwater of the study area were $\mathrm{Na}^{+}>\mathrm{K}^{+}>$ $\mathrm{Ca}^{2+}>\mathrm{Mg}^{2+}>\mathrm{Fe}$. The average concentration of chloride in surface water of the area was found to be $57.12 \mathrm{mg} / \mathrm{L}$, which can be considered as safe for all plants. Although chloride is essential to plants in very low amounts, it can cause toxicity to sensitive crops at high concentrations. According to Mass (Mass 1990), a $\mathrm{Cl}^{-}$concentration below $70 \mathrm{mg} / \mathrm{L}$ is generally safe for all plants. $\mathrm{PO}_{4}{ }^{3-}$ was below the detectable limit (BDL) in all DTW. The highest concentration of $\mathrm{PO}_{4}{ }^{3-}$ was found in the river water with a concentration of $2.26 \pm 0.20 \mathrm{mg} / \mathrm{L}$, which may be from agricultural non-point sources. The highest concentration of $\mathrm{PO}_{4}{ }^{3-}$ found in the STW was $2.33 \pm 0.02 \mathrm{mg} / \mathrm{L}$. A maximum concentration of $\mathrm{SO}_{4}{ }^{2-}$ in the surface water was $68.85 \mathrm{mg} / \mathrm{L}$. The average concentration of $\mathrm{SO}^{2-}$ for river water, STW and DTW were 44.82, 38.95 and $26.06 \mathrm{mg} / \mathrm{L}$, respectively (Fig. 4). The anion trend in both surface and groundwater of the study area were $\mathrm{Cl}^{-}>\mathrm{SO}_{4}{ }^{2-}>$ $\mathrm{PO}_{4}{ }^{3-}$. The surface and groundwater samples of the study area individually show deviation with their respective categories. Th e total hardness (TH) of surface water varied from 40.49 to $423.36 \mathrm{mg} / \mathrm{L}$ with an average value of 168.68 $\mathrm{mg} / \mathrm{L}$. According to the $\mathrm{TH}$ classification (Sawyer and McCarty 1967), the surface water of the study area is hard (150-300 mg/L). The average values of TH in STW and DTW of the study area was found to be 435.540 and 198.31 $\mathrm{mg} / \mathrm{L}$ (Table 1), which falls within the category of very hard (>300 mg/L) and hard (150-300 mg/L), respectively.

The KR of the collected surface water samples ranged from 0.841 to 5.206 with an average value of 3.88 . The shallow and deep groundwater sources had average values

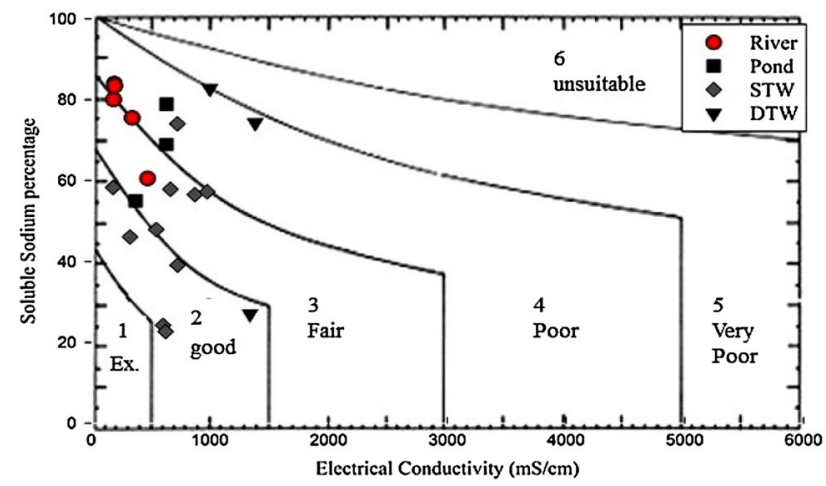

Fig. 4 Wilcox's diagram (Wilcox 1948) for irrigation water classification of the sampling sites of 1.29 and 2.83 , respectively. The river water of the study area (S-5, S-6, S-7) has high Kelly's ratio, (Table 1) and DTW compared to STW has a high ratio (S-20, S-21). It can be concluded that the surface water, especially river water and deep groundwater is subjected more to sodium hazard. MAR causes a harmful effect when it exceeds a value of 50 (Gupta and Gupta 1987). In the study area, the entire surface water samples had acceptable MAR value within the guideline except $\mathrm{S}-6$, which was a river sample (Table 1). All the samples from STW and DTW had permitted MAR values except S-20 and S-21 which were both DTW $>50$.

At the same level of salinity and SAR, adsorption of $\mathrm{Na}^{+}$by soils and clay minerals was greater at higher $\mathrm{Mg}: \mathrm{Ca}$ ratios. This is because the bonding energy of $\mathrm{Mg}^{2+}$ is less than that of $\mathrm{Ca}^{2+}$, allowing more $\mathrm{Na}^{+}$adsorption and happens when the ratio exceeds 4.0 (Michael 1992). Ayers and Westcot (1985) also reported that soil containing high levels of exchangeable $\mathrm{Mg}^{2+}$ caused an infiltration problem. In the study area, the ratio of $\mathrm{Mg}^{2+}$ and $\mathrm{Ca}^{2+}$ for surface water ranged from 0.385 to 0.821 and the average value was 0.48 . The STW water and DTW water samples have an average $\mathrm{Mg}$ :Ca ratio of 0.39 and 0.60 , respectively. From Table 3, it is apparent that in the study area, the ratio of $\mathrm{Mg}^{2+}$ and $\mathrm{Ca}^{2+}$ for all the surface and groundwater was less than 1.0. Thus, it indicates a good proportion of $\mathrm{Ca}^{2+}$ and $\mathrm{Mg}^{2+}$, which maintains a good structure with no permeability problem of the soil in the area. However, considering $\mathrm{Na} \mathrm{Ca}$ ratio, STW showed high suitability as irrigation water. The presence of excessive $\mathrm{Na}^{+}$in irrigation water promotes soil dispersion and structure breakdown when $\mathrm{Na}^{+}$and $\mathrm{Ca}^{2+}$ ratios exceed 3:1. Such a high $\mathrm{Na}: \mathrm{Ca}$ ratio $(>3: 1)$ results in severe water infiltration problems, mainly due to lack of sufficient $\mathrm{Ca}^{2+}$ to counter the dispersing effect of $\mathrm{Na}^{+}$(Table 1). Excessive $\mathrm{Na}^{+}$also creates problem in crop water uptake, poor seedling emergence, lack of aeration, plant and root decreases, etc. (Ayers and Westcot 1985). Surface water (especially river water) and DTW of the area had higher $\mathrm{Na}$ :Ca value.

Salinity classification given by the US salinity laboratory (Richards 1954) classifies 16 classes, with reference to SAR as an index of sodium hazard and EC as an index of salinity hazard (Michael 1992; Mirsa and Ahmed 1987). SAR is expressed in terms of classification of irrigation water as low (S1: <10), medium (S2: 10-26), high (S3: 18-26) and very high (S4: <26), (Richards 1954). A high SAR value implies a hazard of sodium replacing $\mathrm{Ca}^{2+}$ and $\mathrm{Mg}^{2+}$ in the soil through a cation exchange process that damages the soil structure, mainly permeability, and ultimately affects the fertility status of the soil and reduce crop field (Gupta 2005). The SAR value of surface water of the study area ranged from 3.675 to 14.955 with an average value of 9.745 , which can be classified as irrigation water 
of low sodium hazard. The average SAR value of STW water and DTW water of the study area were 5.575 and 11.633, which can be considered as irrigation water with low sodium hazard and that with medium sodium hazard, respectively.

From Fig. 3, it is apparent that out of ten STW samples, nine $(90 \%)$ fell under $\mathrm{C} 1-\mathrm{S} 1$, indicating low alkali and low salinity hazard, while only one sample fell under medium sodium hazard. Among the three DTW sample, one fell in the C1-S3 group, indicating high sodium hazard but low salinity hazard; one fell under $\mathrm{C} 2-\mathrm{S} 2$, indicating medium alkali and medium salinity hazard; and one fell under C2$\mathrm{S} 1$ group, indicating medium salinity hazard but low alkali hazard. Among the three pond water samples, two fell under $\mathrm{C} 1-\mathrm{S} 1$, that is, low hazard in terms of both salinity and sodium hazard, while one sample fell under low salinity hazard but medium alkali hazard. Among the five river water samples, two fell in $\mathrm{C} 1-\mathrm{S} 1$ (low hazard in terms of both salinity and sodium) and three fell under the C2-S1 group, indicating medium salinity hazard but low alkali hazard. On the other hand, surface water contained $50 \%$ of medium sodium hazard-low salinity hazard making it unsuitable for irrigation purposes.

The soluble sodium percentage (SSP) is also widely utilized for evaluating the suitability of water quality for irrigation (Wilcox 1948). The SSP is computed with respect to relative proportions of cations present in water, where the concentrations of ions are expressed in meq/L. Excess $\mathrm{Na}^{+}$, combined with carbonate, leads to the formation of alkaline soil, whereas with $\mathrm{Cl}^{-}$saline soil is formed. Neither soil will support plant growth. The SSP value of surface water ranged from 46.03 to 83.968 with coverage value of 69.52 . The SSP value of groundwater of the study area ranged from 22.67 to 82.76 with an average of 49.292. Wilcox's diagram (Wilcox 1948) is especially implemented to classify groundwater quality for irrigation, wherein the EC of water is plotted against SSP (Fig. 4). Out of nine STW, $55.55 \%$ fell under good class, $44.44 \%$ fell under fair class and one sample fell under poor class. However, out of the three DTW samples, two fell under poor class, while on was of good class. Surface water samples fell under fair to poor class of irrigation water quality. Therefore, from both diagrams of salinity hazard classification and Wilcox diagram for irrigation water classification, it is clear that STW was an excellent source of irrigation containing low alkali and low sodium hazard and good to fair class of water.

Correlation coefficient is normally measured to establish the relationship between two variables. On the other hand based on the correlation coefficients, principal component analysis (PCA) is a method complementary to classical approaches of hydrogeochemical research (Morell et al. 1996). PCA provides quick visualization and shows correlation among different water quality variables. The correlation matrices for EC, TDS, major ions and TH with respect to nine other anions and cations were prepared and illustrated (Table 2). EC and TDS showed a strong positive correlation with $\mathrm{Ca}^{2+}$ and $\mathrm{Mg}^{2+}$. $\mathrm{TH}$ showed strong positive correlation toward EC, TDS, $\mathrm{Ca}^{2+}(r \approx 0.95), \mathrm{Mg}^{2+}$ $(r \approx 0.89)$ and $\mathrm{PO}_{4}{ }^{3-} \cdot \mathrm{Mg}^{2+}$ showed a strong correlation toward $\mathrm{Ca}^{2+}(r \approx 0.86)$. This also indicated that the water samples of the area were hard, which was also evident from the $\mathrm{TH}$ classification of the samples. This also signifies a positive and strong correlation with EC and TDS, indicating that the ions originated from the same sources of water.

PCA on the combined datasets with nine anions and cations in relation to EC, TDS and TH provided five factors with eigenvalue $>1$ that can explain approximately $84.24 \%$ of the variability of the data (PC 1 variance of $32.10 \%$ and PC 2 variance of $15.77 \%$ ) (Table 3). When two variables are far from the center and close to each other, they are significantly positively correlated $(r \approx 1)$. Therefore, $\mathrm{PC} 1$ may represent the anions and cations that represent $\mathrm{TH}\left(\mathrm{Ca}^{2+}, \mathrm{Mg}^{2+}, \mathrm{Fe}, \mathrm{PO}_{4}{ }^{3-}\right.$ and $\left.\mathrm{SO}_{4}{ }^{2-}\right)$, while $\mathrm{PC} 2$ in relation to anions and cations represents the salinity (EC and TDS with $\mathrm{Na}^{+}, \mathrm{K}^{+}, \mathrm{Cl}^{-}$) of the water samples (Fig. 5). The elevated EC, $\mathrm{Cl}^{-}$and high content of $\mathrm{Na}^{+}$ relative to $\mathrm{Ca}^{2+}, \mathrm{Mg}^{2+}$ and $\mathrm{K}^{+}$samples suggest their saline origin and brackish nature of DTW and surface water, which agrees with the previous study (Halim et al. 2009; Bahar and Reza 2010). Salinity, TH and $\mathrm{Na}^{+}, \mathrm{K}^{+}, \mathrm{Cl}^{-}$ions indicate that most of the surface water and DTW samples might be affected by the seawater influence and hydrogeochemical processes and may not be suitable for irrigation in the pre-monsoon season.

\section{Discussion}

River water and the DTW in the study area are more endangered to sodium hazard compared to shallow groundwater in the study area. The ratio of $\mathrm{Ca}^{2+}$ and $\mathrm{Mg}^{2+}$ of all water samples indicated that there was no permeability problem of the soil. Considering $\mathrm{Na}$ :Ca ratio, the STW showed high suitability for irrigation. Moreover, simultaneous decrease in good-quality water resources emphasizes the need of using surface water and groundwater resources conjunctively for irrigation. The conjunctive use allows the utilization of poor-quality water, which cannot be used as such for crop production due to its harmful effect on soil and crop health (Singh 2014). Analysis of secondary electrical conductivity (Ec) data of Madhumati River from 2004 to 2011 with each month interval indicated that the temporal variation of salinity increased from the month of December (pre-monsoon season) and reached its highest peak in May, followed by a 
Table 2 Pearson correlation matrix for irrigation water samples $(n=21)$ collected from Gopalganj Sadar Upazila

\begin{tabular}{|c|c|c|c|c|c|c|c|c|c|c|c|c|}
\hline & $\mathrm{pH}$ & $\mathrm{EC}$ & TDS & $\mathrm{Ca}^{2+}$ & $\mathrm{Mg}^{2+}$ & $\mathrm{Na}^{+}$ & $\mathrm{K}^{+}$ & $\mathrm{Fe}$ & $\mathrm{SO}_{4}{ }^{2-}$ & $\mathrm{PO}_{4}{ }^{3-}$ & $\mathrm{Cl}^{-}$ & $\mathrm{TH}$ \\
\hline $\mathrm{pH}$ & 1 & & & & & & & & & & & \\
\hline $\mathrm{EC}$ & -0.38 & 1 & & & & & & & & & & \\
\hline TDS & -0.38 & $0.99 *$ & 1 & & & & & & & & & \\
\hline $\mathrm{Ca}^{2+}$ & -0.25 & $0.56^{*}$ & $0.56^{*}$ & 1 & & & & & & & & \\
\hline $\mathrm{Mg}^{2+}$ & -0.14 & $0.69^{*}$ & $0.69^{*}$ & $0.86^{*}$ & 1 & & & & & & & \\
\hline $\mathrm{Na}^{+}$ & 0.11 & 0.20 & 0.20 & -0.25 & 0.06 & 1 & & & & & & \\
\hline $\mathrm{K}^{+}$ & 0.41 & 0.21 & 0.21 & 0.06 & 0.16 & 0.12 & 1 & & & & & \\
\hline $\mathrm{Fe}$ & -0.03 & 0.09 & 0.09 & $0.49 *$ & 0.34 & $-0.435^{*}$ & 0.15 & 1 & & & & \\
\hline $\mathrm{SO}_{4}^{2-}$ & -0.10 & 0.12 & 0.12 & 0.33 & 0.24 & -0.07 & 0.04 & -0.12 & 1 & & & \\
\hline $\mathrm{PO}_{4}{ }^{3-}$ & -0.22 & -0.02 & -0.02 & 0.15 & -0.05 & 0.03 & -0.16 & 0.14 & 0.06 & 1 & & \\
\hline $\mathrm{Cl}^{-}$ & -0.21 & 0.07 & 0.07 & -0.03 & 0.04 & 0.19 & -0.20 & 0.05 & -0.23 & -0.23 & 1 & \\
\hline $\mathrm{TH}$ & -0.21 & $0.60 *$ & $0.61 *$ & $0.95^{*}$ & $0.89 *$ & -0.16 & 0.04 & 0.32 & $0.48^{*}$ & 0.06 & -0.04 & 1 \\
\hline
\end{tabular}

Two-tailed test of significance is used

* Correlation is significant at the $0.05 \%$ level

Table 3 Extracted eigenvectors for coefficients of principal component analysis (PCA) of irrigation water samples collected from Gopalganj Sadar Upazila

\begin{tabular}{lcc}
\hline & Coefficients of PC1 & Coefficients of PC2 \\
\hline $\mathrm{pH}$ & -0.17071 & -0.04712 \\
$\mathrm{Ec}$ & 0.40078 & 0.32411 \\
$\mathrm{TDS}$ & 0.40122 & 0.32348 \\
$\mathrm{Ca}^{2+}$ & 0.4372 & -0.22972 \\
$\mathrm{Mg}^{2+}$ & 0.44024 & 0.03141 \\
$\mathrm{Na}^{+}$ & -0.02643 & 0.59473 \\
$\mathrm{~K}^{+}$ & 0.07151 & 0.1106 \\
$\mathrm{Fe}^{2-}$ & 0.17795 & -0.4277 \\
$\mathrm{SO}_{4}{ }^{2-}$ & 0.16783 & -0.15239 \\
$\mathrm{PO}_{4}{ }^{3-}$ & 0.03411 & -0.23592 \\
$\mathrm{Cl}^{-}$ & 0.00811 & 0.29081 \\
$\mathrm{Total}^{-}$hardness & 0.44432 & -0.1484 \\
Eigenvalue & 4.33 & 1.78 \\
Percentage of variance & $36.15 \%$ & $14.86 \%$ \\
Total variance & $47.87 \%$ (approx.) \\
\hline
\end{tabular}

declining trend in June (Fig. 6). The reason for the salinity increase from January to May is the low flow from Ganges and low rainfall as well as inflow of saline water from the Bay of Bengal. April and May are regarded as the most salinity-affected months with the level of salinity reaching to $2.36 \pm 1.71$ and $2.35 \pm 1.88 \mathrm{dS} / \mathrm{m}$, respectively. With the setting of the hydrological season in June, enough rainfall runoff and upstream river discharge, the salinity level falls down.

In Bangladesh, deep wells were originally drilled to avoid salinity in shallow groundwater (Ravenscroft et al.

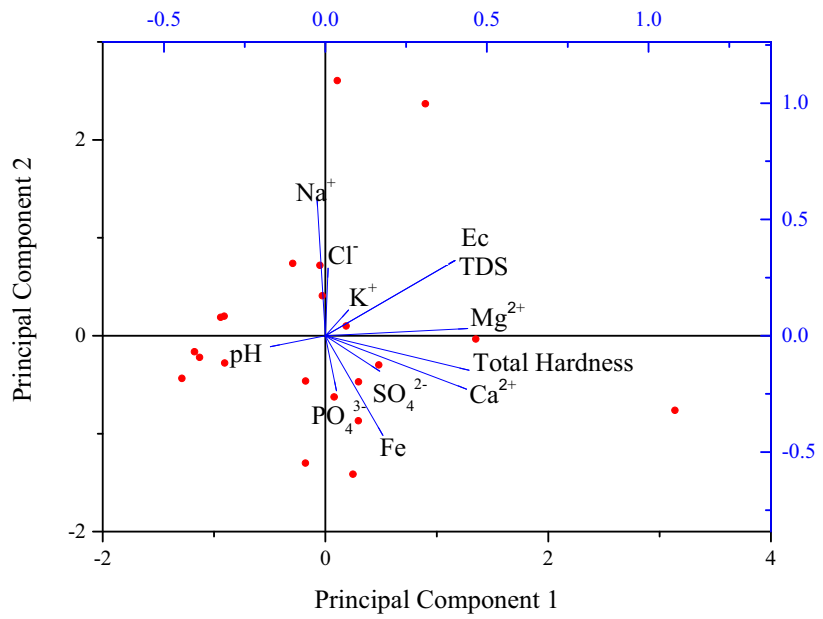

Fig. 5 PCA of the sample water of Gopalganj Sadar Upazila

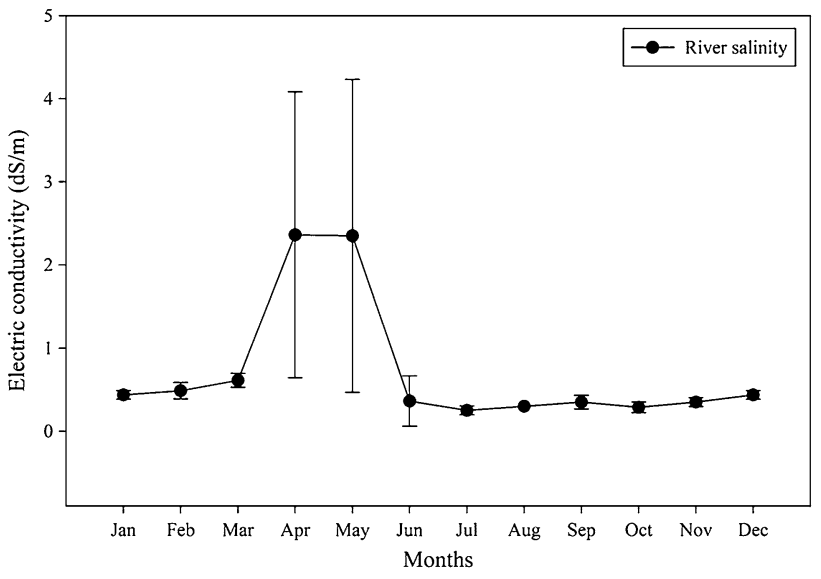

Fig. 6 Electric conductivity EC (dS/m) of Madhumoti River (2004-2011). Vertical and capped bars indicate standard deviation of the means 
2013). However, it is evidenced from the study that DTW of the study area was rather unsafe and is a potential source of salinity hazard. By considering the salinity and sodium hazard of all water sources, it can be recommended that STW is the best source for irrigation compared to others, although heavy withdrawal might lead to the intrusion of brackish water in the shallow aquifer and adversely affect drinking water resources. Utilization of river water and DTW when salinity levels are low during the monsoon season simultaneously can ensure conjunctive utilization and sustainable water resources. Conjunctive use of poorquality water has many benefits, which include increasing the agricultural production and productivity by maintaining effective leaching of the root zone, reducing salt export requirements to prevent groundwater degradation and controlling the waterlogging of the root zone. According to the Department of Environment (MOEF/DoE/GOB 1997), EC for irrigation water should be $2.25 \mathrm{dS} / \mathrm{m}$. So it can be suggested that from March to end of May, farmers should avoid surface water from river for irrigation. Additionally, it is also revealed that the careful and efficient management of irrigation with saline water can leave the groundwater salinity levels unaffected (Malash et al. 2008).

However, despite several advantages, the conjunctive use of poor-quality water has some limitations as well, i.e., salinity buildup (Singh 2014). Blending and cyclic use are two options available for the conjunctive use of different qualities of water. The good-quality water is mixed with the poor one in a certain proportion before applying to the field in the blending mode, while two water sources are used alternately in the cyclic mode (Ayers and Westcot 1985; Rhoades 1990). Nevertheless, considering the existing situation, the blending mode is not possible, which left with the options of cyclic mode of using poor-quality saline water through seasonal variation. Various seasonal modes of using saline and goodquality waters for growing sensitive and salt-tolerant crops were advocated by Rhoades (1989). Various combinations for using saline and good-quality waters should be considered for winter irrigation season. Besides that, excavation of ponds and storing rainwater is a good way to mitigate irrigation water scarcity in the affected area. During dry periods, this pond water can be utilized for irrigation practices. Moreover, it is necessary to bring down the salinity from soil by leaching salts from land. Application of simple ashes and biochar can ameliorate salt stress effects on plants through salt sorption, suggesting novel applications of biochar to mitigate the effects of salinization in agriculture (Thomas et al. 2013). Biochar addition reduced plant sodium uptake by transient $\mathrm{Na}^{+}$binding due to its high adsorption capacity, decreasing osmotic stress by enhancing soil moisture content and by releasing mineral nutrients (particularly
$\mathrm{K}^{+}, \mathrm{Ca}^{2+}, \mathrm{Mg}^{2+}$ ) into the soil solution (Akhtar et al. 2015). Taking this into account, further research can be taken in the saline-affected areas of the country to ameliorate salt stress in agricultural production.

\section{Conclusion}

Irrigation water quality is largely influenced by the existing anions and cations in the water. The sustainability of irrigated agriculture in coastal Bangladesh is in jeopardy because of dwindling water supplies from overextraction, seawater intrusion and low flow from upstream and climate change impacts. The presence of high salinity can deteriorate the soil properties of valuable agricultural land as well as damage crop production. It is palpable that a large production in the agricultural sector is highly dependent on good quality of irrigation water. However, because of increasing salinity trend in Bangladesh, many areas of the country have started to realize the impact of using poor-quality water for irrigation. The presence of high salinity and sodicity in irrigation water can deteriorate the soil properties of valuable agricultural land as well as damage crop production. So, it is very important to assess the salinity hazard of irrigation water sources of any agricultural area to earn maximum agricultural yield. Gopalganj District in Bangladesh is a highly potential district in terms of agriculture and fisheries. The conjunctive use of surface water and groundwater resources can solve the water shortages problem of irrigated agriculture up to some extent in the study area. It also allows the utilization of poor-quality saline water, which cannot be used per se for crop production due to its harmful effect on soil and crop health sustainably.

\section{Compliance with ethical standards}

Conflict of interest The authors declare no conflict of interest.

\section{References}

Akhtar S, Andersen M, Liu F (2015) Residual effects of biochar on improving growth, physiology and yield of wheat under salt stress. Agric Water Manag 158:61-68. doi:10.1016/j.agwat. 2015.04.010

Alrajhi A, Beecham S, Bolan NS, Hassanli A (2015) Evaluation of soil chemical properties irrigated with recycled wastewater under partial root-zone drying irrigation for sustainable tomato production. Agric Water Manag 161:127-135. doi:10.1016/j. agwat.2015.07.013

APHA (1998) Standard methods for the examination of water and wastewater. American Public Health Association, Port City Press, Maryland

Ayers RS, Westcot DW (1985) Water quality for agriculture. Irrigation and drainage. Paper No. 29. Food and Agriculture Organization of the United Nations, Rome, Italy, pp 1-117 
Bahar MM, Reza MS (2010) Hydrochemical characteristics and quality assessment of shallow groundwater in a coastal area of Southwest Bangladesh. Environ Earth Sci 61(5):1065-1073. doi:10.1007/s12665-009-0427-4

Bhuiyan MJAN, Dutta D (2012) Assessing impacts of sea level rise on river salinity in the Gorai river network, Bangladesh. Estuar Coast Shelf S 96:219-227. doi:10.1016/j.ecss.2011.11.005

Fasakhodi AA, Nouri SH, Amini M (2010) Water resources sustainability and optimal cropping pattern in farming systems; a multi-objective fractional goal programming approach. Water Resour Manage 24(15):4639-4657

Foster S, van Steenbergen F (2011) Conjunctive groundwater use: a 'lost opportunity' for water management in the developing world? Hydrogeol J 19(5):959-962

Gupta PK (2005) Methods in environmental analysis: water, soil and air. Agrobios, Jodhpur, pp 1-127

Gupta SK, Gupta IC (1987) Management of saline soils and water. Oxford and IBH publication Co., New Delhi, p 399

Halim MA, Majumder RK, Nessa SA, Hiroshiro Y, Uddin MJ, Shimada J, Jinno K (2009) Hydrogeochemistry and arsenic contamination of groundwater in the Ganges Delta Plain, Bangladesh. J Hazard Mater 164(2-3):1335-1345. doi:10.1016/ j.jhazmat.2008.09.046

Huq SMI, Alam MD (2005) A handbook on analyses of soil, plant and water. BACER-DU, University of Dhaka, Bangladesh. ISBN 984-32-1770-5

Isaaks EH, Srivastava RM (1989) Applied geostatistics. Oxford University Press, New York, p 561

Islam MS, Shamsad SZKM (2009) Assessment of irrigation water quality of Bogra District in Bangladesh. Bangladesh J Agric Res 34(4):597-608

Jang CS, Chen SK, Kuo YM (2012) Establishing an irrigation management plan of sustainable groundwater based on spatial variability of water quality and quantity. J Hydrol 414-415:201-210. doi:10.1016/j.jhydrol.2011.10.032

Kaur R, Paul M, Malik R (2007) Impact assessment and recommendation of alternative conjunctive water use strategies for salt affected agricultural lands through a field scale decision support system-a case study. Environ Monit Assess 129:257-270

Kelly WP (1963) Use of saline irrigation water. Soil Sci 95(4):355-391

Khodapanah L, Sulaiman WNA, Khodapanah N (2009) Groundwater quality assessment for different purposes in Eshtehard district, Tehran, Iran. Eur J Sci Res 36(4):543-553

Liu L, Cui Y, Luo Y (2013) Integrated modeling of conjunctive water use in a river-well irrigation district in the lower Yellow River Basin, China. J Irrig Drain Eng ASCE 139(9):775-784

Malash NM, Flowers TJ, Ragab R (2008) Effect of irrigation methods, management and salinity of irrigation water on tomato yield, soil moisture and salinity distribution. Irrig Sci 26:313-323

Mass EV (1990) Crop salt tolerance. In: Tanji KK (ed) Agricultural salinity and assessment management manual. ASCE, Manuals and Reports on Engineering No. 71, ASCE, New York, pp 262-304

Michael AM (1992) Irrigation theory and practices. Vikash Publishing House Pvt. Ltd., New Delhi

Mirsa RD, Ahmed M (1987) Manual of irrigation agronomy. Oxford and IBH Publishing Co. Pvt. Ltd, New Delhi, pp 248-271

MOEF/DoE/GOB (1997) The environment conservation rules 1997. Bangladesh Gazette no. DA-1, Ministry of Environment and Forest, Dhaka, Bangladesh, pp 1324-1327
Morell I, Giménez E, Esteller MV (1996) Application of principal components analysis to the study of salinization on the Castellon Plain (Spain). Sci Total Environ 177(1-3):161-171

Raghunath IIM (1987) Groundwater, 2nd edn. Wiley Eastern Ltd., New Delhi

Rahman SA, Hussain MS, Parveen Z, Mohiuddin ASM (1993) Identifying characteristics of potential and actual acids sulphate soils. Bangladesh J Soil Sci 24:41-49

Rahman MH, Lund T, Bryceson I (2011) Salinity impacts on agrobiodiversity in three coastal, rural villages of Bangladesh. Ocean Coast Manag 54(6):455-468. doi:10.1016/j.ocecoaman.2011.03. 003

Rahman MATMT, Rahman SH, Majumder RK (2012) Groundwater quality for irrigation of deep aquifer in southwestern zone of Bangladesh. Songklanakarin J Sci Technol 34(3):345-352

Ravenscroft P, McArthur JM, Hoque MA (2013) Stable groundwater quality in deep aquifers of Southern Bangladesh: the case against sustainable abstraction. Sci Total Environ 454-455:627-638. doi:10.1016/j.scitotenv.2013.02.071

Rhoades JD (1989) Intercepting, isolating and re-using drainage waters for irrigation to conserve water and protect water quality. Agric Water Manage 16:37-52

Rhoades JD (1990) Strategies to facilitate the use of saline waters for irrigation. Water soil and crop management relating to use of saline water. FAO, Rome, pp 125-136

Richards LA (1954) Diagnosis and improvement of saline and alkali soils. U.S. Department of Agricultural Hand-book, Washington 60:160

Sawyer CN, McCarty PL (1967) Chemistry for sanitary engineers. McGraw-Hill, New York

Shahid S, Chen X, Hazarika MK (2006) Evaluation of groundwater quality for irrigation in Bangladesh using geographic information system. J Hydrol Hydromech 54(1):3-14

Shammi M, Bhuiya GMJA, Ibne Kamal AK, Rahman MR, Rahman MM, Uddin MK (2012) Investigation of salinity occurrences in Kumar-Madhumati River of Gopalganj District, Bangladesh. J NatSci Sustain Technol 6(4):299-313

Singh A (2014) Conjunctive use of water resources for sustainable irrigated agriculture. J Hydrol 519:1688-1697. doi:10.1016/j. jhydrol.2014.09.049

Thomas SC, Frye S, Gale N, Garmon M, Launchbury R, Machado N, Melamed S, Murray J, Petroff A, Winsborough C (2013) Biochar mitigates negative effects of salt additions on two herbaceous plant species. J Environ Manage 129:62-68. doi:10.1016/j. jenvman.2013.05.057

Todh DK (1980) Groundwater hydrology. Wiley International Edition, John Wiley and Sons. Inc., New York

Tyagi NK (2003) Managing saline and alkali water for higher productivity. In: Kijne JW, Barker R, Molden D (eds) Water productivity in agriculture: limits and opportunities for improvement. CABI Publishing, Wallingford, UK, pp 69-88

USDA/Salinity Laboratory Staff (1954) Diagnosis and improvement of saline and alkali soil. US Department of Agricultural Hand Book 60, Washington

Wilcox LV (1948) The quality of water for irrigation use. US Department of Agricultural Technical Bulletin 1962, Washington 